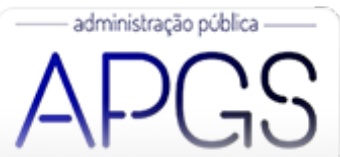

Administração Pública e Gestão Social ISSN: 2175-5787

apgs@ufv.br

Universidade Federal de Viçosa

Brasil

\title{
A Distribuição dos Royalties do Petróleo e a Eficiência na Gestão Financeira dos Municípios do Estado de São Paulo
}

Schiavoni Froemming, Douglas; Augusto do Rosário Contani, Eduardo; Reed Bergmann, Daniel; Lopes da Silva, Fabiana

A Distribuição dos Royalties do Petróleo e a Eficiência na Gestão Financeira dos Municípios do Estado de São Paulo

Administração Pública e Gestão Social, vol. 12, núm. 2, 2020

Universidade Federal de Viçosa, Brasil

Disponible en: http://www.redalyc.org/articulo.oa?id=351562414003

Esta obra está bajo una Licencia Creative Commons Atribución-NoComercial-SinDerivar 3.0 Internacional. 


\title{
A Distribuição dos Royalties do Petróleo e a Eficiência na Gestão Financeira dos Municípios do Estado de São Paulo
}

\author{
The distribution of oil royalties and efficiency in financial management of municipalities of São Paulo state \\ La distribución de las regalías del petróleo y la eficiencia en la gestión financiera de los municipios del e stado de São \\ Paulo
}

Douglas Schiavoni Froemming

Secretaria da Fazenda e Planejamento do Estado de São

Redalyc: http://www.redalyc.org/articulo.oa?

Paulo, Brasil

froemmingds@gmail.com

Eduardo Augusto do Rosário Contani

Universidade Estadual de Londrina, Brasil

eduardo.contani@fecap.br

Daniel Reed Bergmann

Universidade de São Paulo, Brasil

danielrb@usp.br

Fabiana Lopes da Silva

Fundação Instituto de Pesquisas Contábeis, Atuariais e

Financeiras, Brasil

fabiana.silva@fipecafi.org $\mathrm{id}=351562414003$

\author{
Recepción: 06 Agosto 2017 \\ Aprobación: 14 Diciembre 2018 \\ Publicación: 01 Abril 2020
}

\section{Resumo:}

A Lei do Petróleo trouxe para alguns municípios uma nova fonte de recursos, disponibilizada pela distribuição dos royalties. Questiona-se se não há, por parte desses municípios, um relaxamento no esforço fiscal e aumento da ineficiência. Este estudo tem por objetivo verificar se os royalties contribuem para o aumento das ineficiências nos municípios envolvidos em sua busca pelas receitas próprias. Foram selecionados 56 municípios do estado de São Paulo, durante o período compreendido entre os anos de 2005 e 2012. Para medir a eficiência foi utilizada a Análise Envoltória de Dados (Data Envelopment Analysis [DEA]). A análise de Regressão Logística foi utilizada com o intuito de identificar quais variáveis provocaram as ineficiências nos municípios analisados. Os resultados mostraram que os royalties distribuídos aos municípios paulistas possuem grande variabilidade e são relevantes apenas em alguns deles. Não houve diferença significativa no esforço fiscal dos municípios afetados pela variável royalties de petróleo.

PaLAVRas-CHAVE: Finanças públicas, Royalties de petróleo, Eficiência - DEA, Regressão logística, Esforço fiscal.

\section{Abstract:}

The Oil Act brought to some municipalities a new source of funds, made available through the distribution of royalties. It is questioned if there is, on the part of these municipalities, a relaxation in the fiscal effort and increase of the inefficiency. This study aims to verify if the royalties contribute to the increase of the inefficiencies in the municipalities involved in their search for the own revenues. 56 municipalities in the State of São Paulo were selected during the period from 2005 to 2012. To measure efficiency, Data Envelopment Analysis (DEA) was used. The Logistic Regression analysis was used to identify which variables caused the inefficiencies in these municipalities. The results showed that the royalties distributed to the municipalities of São Paulo have great variability and are relevant only in some of them. There was no significant difference in the fiscal effort of the municipalities affected by the oil royalties variable.

KEYWORDS: Public finance, Oil royalties, Efficiency - DEA, Logistic regression, Fiscal effort. 


\section{Resumen:}

La Ley del Petróleo trajo a algunos municipios una nueva fuente de fondos, puesta a disposición mediante la distribución de regalías. Se cuestiona si no hay, por parte de estos Municipios, una relajación en el esfuerzo fiscal y aumento de la ineficiencia. Este estudio pretende verificar si las regalías contribuyen al aumento de las ineficiencias en los municipios involucrados en su búsqueda de ingresos propios. Se seleccionaron 56 municipios del Estado de São Paulo, durante el período comprendido entre 2005 y 2012. Para medir la eficiencia, se utilizó el Análisis de Envoltura de Datos (DEA). El análisis de Regresión Logística fue utilizada para identificar qué variables causaron las ineficiencias en estos municipios. Los resultados mostraron que las regalías distribuidas a los municipios de São Paulo tienen gran variabilidad y sólo son relevantes en algunos de ellos. No hubo diferencias significativas en el esfuerzo fiscal de los municipios afectados por la variable de regalías petroleras.

Palabras clave: Finanzas públicas, Regalías petroleras, Eficiencia - DEA, Regresión logística, Esfuerzo fiscal.

\section{INTRODUÇÃo}

A Constituição de 1988 elevou os municípios brasileiros à condição de entes federativos em uma delegação de competências que aumentou responsabilidade municipal na execução de políticas públicas.

No entanto, as disparidades regionais e sociais dificultam a proposição de soluções passíveis de serem conciliadas entre a descentralização fiscal, o equilíbrio federativo e a eficiência na gestão pública. Além disso, as medidas tomadas pelos municípios têm efeitos locais e são prontamente percebidas por seus habitantes e usuários, ou seja, os efeitos de uma administração financeira local mais ou menos eficiente são quase que imediatamente sentidos pela municipalidade.

Adicionalmente, a Lei no 9.478, de 6 de agosto de 1997, comumente conhecida como Lei do Petróleo, determinou que uma parte do valor bruto de produção do petróleo e de gás natural deve ser recolhido na forma de royalties e participações especiais, sendo que uma parte destes recursos é distribuída aos estados e municípios diretamente afetados pela produção segundo critérios geográficos (Lei n. 9.478, de 6 de agosto de 1997, 1997). Uma vez que se trata de uma receita não vinculada, ela passou a causar impacto no orçamento, em maior ou menor grau, dos municípios envolvidos.

O impacto das rendas do petróleo nos orçamentos municipais trouxe também o questionamento sobre o adequado uso desses recursos. Diversos estudos abordaram os efeitos socioeconômicos destas receitas nas regiões abrangidas: Leal e Serra (2002) estudaram o aumento no volume de investimentos realizados pelos municípios beneficiários da distribuição dos royalties no estado do Rio de Janeiro em comparação com os demais municípios do mesmo estado; Navarro (2003) avaliou a composição das despesas municipais em Campos dos Goytacazes (RJ) em função das receitas dos royalties; Serra (2005) fez um estudo sobre os royalties e se sua distribuição seria capaz de promover a justiça intergeracional; Postali (2009) investigou o impacto da distribuição dos royalties no desenvolvimento dos municípios afetados, utilizando como base os seus Produtos Internos Brutos (PIBs); Nogueira e Ramos (2013) realizaram um estudo utilizando a abordagem da Análise Envoltória de Dados (Data Envelopment Analysis [DEA]) para verificar a eficiência do uso dos recursos provenientes dos royalties nos municípios fluminenses; e Reis e Santana (2015) analisaram os efeitos da aplicação das rendas de petróleo sobre os investimentos públicos nos municípios afetados.

Com o advento da exploração de petróleo na camada do pré-sal, as perspectivas sobre as rendas do petróleo provocaram pressóes para uma mudança na regulamentação da distribuição dos royalties e das participações especiais.

De forma a estender os benefícios provenientes da exploração petrolífera aos demais entes da Federação, foi promulgada a Lei ${ }^{\circ}$ 12.734, de 30 de novembro de 2012, que alterou dispositivos da Lei do Petróleo, incluindo como critérios para distribuição das rendas do petróleo os mesmos utilizados no Fundo de Participação dos Municípios (FPM) (Lei n. 12.734, de 30 de novembro de 2012, 2012). Como consequência, há uma nova fonte de recursos disponibilizada aos cofres municipais e, consequentemente, surge a preocupação sobre quanto é sua adequada utilização. 
Espera-se que os munícipios aproveitem o impacto gerado pela indústria do petróleo e se desenvolvam no sentido de buscar maior independência financeira das transferências intergovernamentais, sobretudo no aumento da eficiência na arrecadação de recursos tributários (esforço fiscal).

No entanto, Shah (1994) identificou uma relação negativa entre as receitas intergovernamentais e o esforço fiscal. No caso brasileiro, o FPM, de origem federal, a Cota-Parte do Imposto sobre Circulação de Mercadorias e Serviços (ICMS), de origem estadual e, por analogia, as receitas dos royalties de petróleo, desencorajariam os esforços fiscais locais, provocando uma dependência cada vez maior de fontes de receitas intergovernamentais e, por consequência, uma redução na responsabilidade financeira por parte dos gestores municipais.

Neste sentido, este trabalho busca responder à seguinte questão de pesquisa: Qual a influência das transferências intergovernamentais e das receitas da exploração do petróleo sobre o esforço fiscal nos municípios paulistas?

Como hipótese da pesquisa, assume-se que os municípios com maior nível de transferências intergovernamentais e de receitas de exploração do petróleo possuem menor esforço fiscal. Isto é, as rendas do petróleo geram ineficiências na gestão da máquina administrativa municipal, sobretudo naquela voltada para a arrecadação de impostos, ou seja, quanto maior a dependência do município de recursos provenientes de rendas do petróleo, pior a eficiência na gestão e na busca por recursos próprios.

Os objetivos deste estudo são: (i) Analisar as variações de desempenho no esforço fiscal dos municípios paulistas em função das receitas intergovernamentais e das rendas do petróleo e (ii) estabelecer um ranking (eficiência) dos municípios do estado de São Paulo, de tal forma que, observando as variáveis em estudo, seja possível estabelecer critérios e metas para que os municípios pouco eficientes possam melhorar seu desempenho e identificar suas falhas.

Apesar de diversos estudos abordarem os efeitos socioeconômicos das receitas do petróleo nas regiões abrangidas (Postali, 2009; Postali \& Nishijima, 2011; Serra, 2003), poucos estudos buscam avaliar os impactos adversos dos royalties sobre a eficiência na gestão municipal (Postali, 2012).

Destaca-se também a relevância dos valores envolvidos na distribuição das rendas de petróleo aos municípios. Segundo dados da Agência Nacional do Petróleo, Gás Natural e Biocombustíveis (ANP) de 2014, apenas no ano de 2012 foram distribuídos cerca de 5,4 bilhões de reais aos municípios brasileiros, sendo que os municípios paulistas receberam $\mathrm{R} \$ 455$ milhões (8,5\% do total distribuído aos municípios).

Diante disso, o presente trabalho justifica-se pela importância em analisar o esforço fiscal municipal, dada sua expressiva participação na geração de serviços públicos; pela relevância dos valores de royalties de petróleo que são distribuídos aos municípios e pela escassez de trabalhos científicos, que relacionam o esforço fiscal com as rendas de royalties de petróleo, diante das alterações legislativas visando ampliar o número de municípios beneficiados por essas participações.

Para a realização deste estudo, foram selecionados os municípios do estado de São Paulo que são beneficiados pelas transferências de royalties e participações especiais. $\mathrm{O}$ estado foi selecionado por sua relevância na economia nacional (representa 33\% do PIB de 2012), por possuir uma economia dinâmica, por ter sido beneficiado pela distribuição das rendas do petróleo, pelos critérios geográficos da Lei $n^{\circ}$ 9.478/97 e por ser formado por diversos tipos de municípios, de diversos tamanhos e capacidades financeiras.

Após a seleção dos municípios e levantamento dos dados necessários ao estudo, foi utilizada a modelagem por Análise Envoltória de Dados (Data Envelopment Analysis - DEA) para determinar a eficiência dos municípios do estado de São Paulo que receberam royalties de petróleo entre os anos de 2005 e 2012. Além disso, diversos estudos sobre eficiência com o uso da abordagem DEA apresentam um segundo estágio de análise envolvendo uma análise de regressão. Neste contexto, a fim de identificar possíveis determinantes desta ineficiência, o segundo estágio ancora-se no modelo de Regressão Logística, diferencial deste trabalho em relação às abordagens da literatura. 
O presente artigo está dividido em cinco seções, incluindo esta introdução. A segunda seção apresenta a plataforma teórica. A terceira seção aborda os aspectos metodológicos. A quarta seção detalha os resultados encontrados e, na última seção, é concluída a pesquisa.

\section{Fundamentação Teórica}

\subsection{Federalismo Fiscal}

De acordo com Diniz (2012), a teoria do federalismo fiscal aborda a divisão de responsabilidade da arrecadação dos recursos financeiros e da distribuição desses recursos para a execução dos gastos públicos nas instâncias de governo.

O conceito de federalismo fiscal está associado às definições de competências tributárias e de responsabilidades de gastos pelas diferentes instâncias da federação. A racionalidade econômica preconiza que os gastos públicos são passíveis de descentralização. Por outro lado, quando se olha para a arrecadação, percebe-se um descompasso, uma vez que o governo federal e os estados possuem instrumentos mais eficientes de arrecadação tributária do que os municípios (Varela, 2008). Este descompasso é verificado entre a execução dos gastos pelos municípios e a arrecadação dos tributos, uma vez que fica a responsabilidade de os municípios promoverem a maioria dos serviços públicos locais.

Para tentar dirimir estas diferenças, existe o sistema de transferências intergovernamentais cuja finalidade, conforme Oates (1972), é equacionar o montante de receitas às necessidades de gastos de uma nação como um todo de maneira eficaz.

$\mathrm{Na}$ visão de Smart (1998), há evidências de que as transferências federais distorcem as alíquotas dos impostos locais, elevando-as. Na mesma linha, o estudo de Sanguinetti e Tommasi (2004) indicam que as transferências interfederativas reduzem o esforço fiscal local pelo excesso de gastos diante de receitas tributárias insuficientes, uma vez que essas rendas proporcionariam uma espécie de seguro contra a queda no nível de atividades, elevando, desta forma, o risco moral da gestão.

No Brasil, os principais estudos sobre as transferências, gastos e tributação surgiram após a Constituição de 1988, em que maiores parcelas de recursos foram destinadas aos estados e aos municípios sem a correspondente responsabilidade pela oferta de bens e serviços à população.

No estudo realizado por Shah (1994) sobre as transferências intergovernamentais em países emergentes foram identificadas evidências de subutilização da base tributária local em função deste tipo de benefício. Segundo Postali (2012), para o caso brasileiro, também são observadas evidências neste sentido, agravandose pelo fato de as transferências acabarem beneficiando os municípios maiores. Já Cossio (1998) identificou evidências da relação inversa entre o esforço fiscal e as transferências intergovernamentais no Brasil, ou seja, municípios dependentes de alta concentração de receitas de transferências tendem a reduzir seu esforço de arrecadação própria.

\subsection{Distribuição de rendas do petróleo no Brasil e eficiência dos municípios}

O marco regulatório do setor de petróleo e gás natural foi estabelecido com a promulgação da Lei n ${ }^{\circ}$ 9.478/97, que instituiu um regime de concessões para os direitos de exploração e produção de petróleo e gás natural, bem como criou a Agência Nacional do Petróleo, Gás Natural e Biocombustíves (ANP), que tem a finalidade de promover a regulação, a contratação e a fiscalização das atividades econômicas integrantes da indústria do petróleo, do gás natural e dos biocombustíveis.

A partir desta lei, somente pode ter início a atividade de exploração e produção de petróleo e (ou) gás natural se houver contrato de concessão entre ANP e o produtor. Os contratos assinados preveem duas fases: 
Fase de exploração, em que há o trabalho de prospecção e pesquisa sobre a viabilidade comercial dos recursos sob responsabilidade do concessionário, e a fase de produção, em que o concessionário produz petróleo e (ou) gás. A primeira fase pode ter até nove anos, ao passo que a segunda fase possui 27 anos de duração e a propriedade dos recursos é transferida ao produtor em troca do pagamento de royalties e, quando for o caso, participações especiais à União (Postali, 2012).

Desde a criação da Petrobras, em 1953, o advento da Lei n ${ }^{\circ}$ 9.478/97 proporcionou uma profunda transformação no mercado brasileiro de petróleo, permitindo o acesso a capital privado nas atividades de exploração e produção, estimulando a concorrência e permitindo um melhor uso das rendas provenientes do petróleo.

Especificamente quanto à distribuição de rendas de petróleo no Brasil, verifica-se que o pagamento dos royalties aos municípios se deve, principalmente, ao período de instabilidade política registrado na década de 1980, antes da promulgação da Constituição de 1988, em que houve vários episódios de barganha política entre as esferas governamentais pela divisão desses recursos e as palavras de ordem no cenário político eram a redemocratização política e a descentralização fiscal (Serra, 2005).

No Brasil, a distribuição dos royalties é concentrada em poucos locais, o que tem sido objeto de controvérsia e questionamento sobre se as localidades afetadas conseguiriam enfrentar os problemas após o esgotamento das jazidas (Serra, 2003). Existe um fundamento para que haja aplicação de parte dos recursos provenientes dos royalties em diversificação produtiva nas regiões petrolíferas.

Além disso, deve-se observar se os benefícios das transferências dos royalties afetam o comportamento dos municípios em seus esforços fiscais na arrecadação de tributos, bem como na eficiência dos gastos administrativos. Ou seja, é de suma importância verificar a eficiência do uso dos recursos provenientes das rendas de petróleo pelos municípios.

Há muitos estudos acadêmicos que utilizam o modelo de DEA para determinar a eficiência de Unidades Tomadoras de Decisão (Decision Making Units [DMUs]), frente à presença de múltiplos produtos.

Trabalhos que utilizaram a metodologia DEA para quantificar eficiência de municípios paulistas são: Campello (2003), que mediu a eficiência na exploração e transformação da base tributária em qualidade de vida, encontrando baixa eficiência de exploração e alta de transformação nos dados avaliados; Lopes e Arvate (2006), que verificaram que o aumento do vertical fiscal imbalance resultou no aumento na eficiência técnica do gasto público local; e Varella (2008), que analisou a eficiência econômica relacionada à atenção básica de saúde e constatou que as transferências incondicionais e sem contrapartida (tais como as transferências constitucionais) contribuíram para o aumento da ineficiência nos gastos públicos com a atenção básica à saúde.

Referências internacionais que utilizam a metodologia DEA para avaliar eficiência de municípios são: Worthington (2000), que realizou um estudo comparativo entre o uso da abordagem DEA e o da fronteira estocástica de custos para 177 governos locais situados no estado australiano de Nova Gales do Sul durante o ano de 1993. Os resultados apontam para correlação positiva entre as despesas físicas (materiais e inventário) e as despesas de capital, e correlação negativa para o número de funcionários; o trabalho de Balaguer-Coll, Prior e Tortosa-Ausina (2007), que quantificou o impacto de variáveis fiscais e políticas sobre a eficiência na prestação de serviços públicos na região de Valência, na Espanha; e Afonso e Fernandes (2008), que realizaram um estudo da eficiência nos gastos públicos em 278 municípios portugueses durante o ano de 2001. Os resultados indicaram que os municípios avaliados podem melhorar a qualidade dos serviços prestados sem necessariamente aumentar os gastos públicos.

Diversos estudos sobre eficiência com o uso da abordagem DEA apresentam um segundo estágio de análise envolvendo uma análise de regressão. Em seu estudo sobre a influência dos royalties de petróleo no esforço fiscal dos municípios brasileiros, Postali (2012) utilizou a regressão quantílica em virtude da grande variabilidade e assimetria dos escores de eficiência encontrados. Diniz (2012) usou o modelo de regressão Generalized Estimating Equations (GEE) para verificar a relação entre as transferências intergovernamentais 
e a eficiência do seu uso nos gastos com educação nos municípios brasileiros. Varela (2008) utilizou o modelo de regressão clássica com os scores de eficiência transformados em seu logaritmo natural para mensurar e explicar as variações de desempenho dos municípios paulistas quanto à eficiência econômica na aplicação de recursos públicos nas ações de atenção básica à saúde. Lopes e Arvate (2006) utilizaram uma regressão linear por Mínimos Quadrados Ordinários.

\section{Metodologia}

Este trabalho tem por objetivo verificar se as rendas do petróleo influenciam no esforço fiscal dos municípios, buscando diferenciar os municípios paulistas que recebem as rendas do petróleo quanto a sua eficiência no esforço arrecadatório e em sua busca por maior independência das transferências intergovernamentais.

Nossa premissa é que as rendas do petróleo geram ineficiências na gestão da máquina administrativa municipal, sobretudo naquela voltada para a arrecadação de impostos. Assim, quanto menor for a dependência do município de recursos provenientes de rendas do petróleo, maior será sua eficiência na gestão e na busca por recursos próprios.

Desta forma, identificam-se quais fatores determinam a eficiência dos municípios, apoiando o estabelecimento de critérios e metas para que os municípios menos eficientes possam identificá-las e corrigir suas falhas. Pretende-se, por fim, estabelecer um ranking (eficiência) dos municípios do estado de São Paulo, de tal forma que se possam estabelecer os critérios necessários para que os municípios não tão eficientes possam identificar suas falhas e melhorar seu desempenho.

Portanto, para se atingir os objetivos propostos, deve-se calcular a fronteira de produção para o processo de exploração das bases e calcular os valores potenciais, advindos da exploração completa da base tributária.

O modelo DEA utilizado no trabalho é um método não paramétrico inicialmente desenvolvido Charnes, Cooper e Rhodes (1978). O modelo permite obter a eficiência quando existem múltiplos inputs e múltiplos outputs e atende ao conceito de eficiência definido por Koopmans (1951) em que: (i) Um produto não pode ser gerado em maior quantidade sem que seja diminuída a quantidade gerada de algum outro produto ou sem que seja aumentada a quantidade consumida de pelo menos um insumo e (ii) um insumo não pode ser consumido em menor quantidade sem que seja aumentada a quantidade consumida de algum outro insumo ou sem que seja diminuída a geração de pelo menos um produto.

Banker, Charnes e Cooper (1984) apresentaram o Modelo Variable Returns to Scale (VRS), que pressupõe retornos variáveis de escala nas unidades avaliadas. Com isso, é possível que a produtividade máxima varie de acordo com a escala de produção, permitindo, portanto, a utilização de DMUs de portes distintos. Utilizando a orientação para os produtos (outputs) o modelo pode ser descrito por:

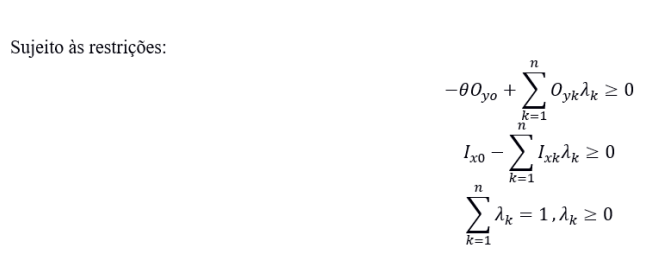

em que $y=1, . ., s ; x=1, \ldots . . ; \theta$ é um escalar que varia de $1 \leq \theta<\infty$ e $\theta-1$ representa o aumento proporcional em outputs que poderiam ser alcançados pela DMU, mantendo a quantidade de inputs constante. Nesse caso, $1 / \theta$ define o score de eficiência, e $\lambda$ é um vetor $\mathrm{Nx} 1$ de constantes.

A eficiência obtida no modelo VRS corresponde a uma medida de eficiência técnica (ET) por estar depurada dos efeitos de escala de produção e, com isso, pode-se construir uma curva de produção que forma o conjunto de produção revelado. Identificam-se as DMUs cujos planos de produção, determinados pelos pesos 
para as quantidades de outputs e inputs, não possam ser superados pelo plano de nenhuma outra unidade. A DMU é considerada eficiente e torna-se referência para as demais, e assim sucessivamente.

Após a utilização da metodologia DEA para a obtenção da fronteira e diferenciar os municípios eficientes dos ineficientes, foi realizada a análise regressão logística para verificar quais variáveis provocaram as ineficiências nos municípios analisados.

A regressão logística busca predizer valores de uma variável em função de valores conhecidos de outras variáveis (Dias Filho \& Corrar, 2007). O modelo matemático da regressão logística consiste em converter a variável dependente em uma razão de chances e depois transformar essa razão de chances na função logística, ou seja, obter o logaritmo natural da razão de chances, conforme explicitado nas equações (2) e (3):

$$
\begin{aligned}
& \text { Razão de Chances }=\frac{\mathrm{P}(\text { sucesso })}{1-\mathrm{P}(\text { sucesso })} \\
& \ln \left(\frac{\mathrm{P}(\text { sucesso })}{1-\mathrm{P}(\text { sucesso })}\right)=\beta_{0}+\beta_{1} x_{1 i}+\beta_{2} x_{2 i}+\ldots+\beta_{k} x_{\mathrm{ki}}
\end{aligned}
$$

A transformação evita a predição de valores menores que zero e maiores que um. Embora a variável dependente só possa assumir duas posiçóes (zero e um), torna-se necessário obter valores que possam ser interpretados em termos de probabilidade.

As variáveis explicativas passam então a expressar mudanças no log da razão das chances, ou seja, a regressão logística calcula mudanças nas inter-relações dos logs da variável dependente e não na própria variável, como ocorre na regressão linear. Desta forma, o coeficiente de cada variável independente exerce efeitos sobre a função logística, sobre a própria razão de chances e, por fim, sobre as probabilidades.

Como os scores de eficiência obtidos por meio da DEA estão entre zero e um, o modelo linear pode mostrar-se inadequado, pois a suposição de normalidade da variável dependente não é satisfeita. A proposta deste trabalho consiste em transformar a variável eficiência em dicotômica, ou seja, assume valor 1 se $o$ município foi classificado como eficiente e 0 em caso contrário $(Y=1$, se a eficiência técnica é igual 1 , ou $\mathrm{Y}=0$, se a eficiência técnica é menor do que 1). Neste caso a variável $Y$ terá distribuição de Bernoulli com probabilidade de sucesso $\mathrm{P}$, sendo $\mathrm{E}[\mathrm{Y}]=\mathrm{P} /(1-\mathrm{P})$ e com isso, a regressão logística mostra-se como uma técnica estatística que permite estimar a probabilidade de ocorrência de determinado evento em face de um conjunto de variáveis explanatórias.

\subsection{Definição das variáveis e modelagem estatística}

Os dados utilizados referem-se aos municípios do estado de São Paulo que receberam royalties de petróleo entre os anos de 2005 e 2012. Verificou-se que 103 municípios paulistas receberam royalties de petróleo em pelo menos um ano do período selecionado. Aqueles municípios que não tinham informações completas quanto às variáveis utilizadas nas análises ou que não receberam os royalties em todos os anos do período selecionado foram descartados, restando um conjunto de 56 municípios sob a análise.

Uma vez que o objeto de estudo deste trabalho são os efeitos da distribuição das rendas de petróleo na gestão administrativa municipal, os royalties de petróleo constituem a principal variável de interesse. Neste trabalho tanto os royalties de petróleo como as participações especiais estão sendo consideradas em conjunto e denominadas apenas de royalties ou rendas de petróleo.

A escolha dos inputs e dos outputs utilizados na metodologia DEA foi baseada nos estudos de Nogueira e Ramos (2013), Postali (2012), Diniz (2012), Varela, Martins e Fávero (2012), Varela (2008), Araújo (2007), Lopes e Arvate (2006) e Campello (2003). Os inputs escolhidos referem-se aos royalties de petróleo, 
às transferências da União e às transferências do estado, recebidos pelos municípios paulistas durante o período de 2005 a 2012. Os dados sobre os royalties de petróleo foram obtidos da ANP e os dados sobre as transferências da União e do estado foram obtidos da Finanças do Brasil/Secretaria do Tesouro Nacional (FINBRA/STN).

As transferências da União são constituídas, basicamente, pelas cotas-parte constitucionais sobre as receitas provenientes da União (Fundo de Participação dos Municípios [FPM], Imposto sobre Operações Financeiras sobre o ouro quando for instrumento financeiro ou ativo cambial [IOF ouro], e o Imposto Territorial Rural), das transferências do Sistema Único de Saúde (SUS) e as relativas aos Fundos Constitucionais (FNDE, FNAS, etc.).

As transferências estaduais também são provenientes de mandamento constitucional e caracterizam-se por cotas-parte sobre as receitas tributárias dos estados, incluindo a participação nos seguintes impostos: Imposto sobre Circulação de Mercadorias e Prestação de Serviços de Transporte Interestadual e Intermunicipal e Comunicações (ICMS), Imposto sobre Veículos Automotores (IPVA) e 25\% da cota-parte dos estados referente ao Imposto sobre Produtos Industrializados (IPI).

Ressalta-se que essas variáveis identificam o grau de dependência orçamentária de um município em relação às instâncias superiores da federação, sobretudo no que diz respeito aos seus componentes constitucionais.

As variáveis que foram escolhidas como outputs representam a arrecadação tributária municipal: Imposto Predial e Territorial Urbano (IPTU), Imposto sobre Serviços de Qualquer Natureza (ISSQN), Imposto sobre Transmissão de Bens Imóveis (ITBI) e as Taxas Municipais. Estes dados foram extraídos da FINBRA/ STN.

Em face dos inputs e dos outputs selecionados temos que, dado um volume de recursos proveniente de royalties de petróleo e de transferências intergovernamentais, em que não há um esforço municipal para sua arrecadação, busca-se verificar qual o comportamento do município em relação a sua arrecadação tributária, que representa o seu esforço fiscal.

As variáveis, tanto para os inputs quanto para os outputs, foram expressas em termos per capita com o intuito de se estabelecer uma diferenciação relativa entre os municípios em face aos seus diferentes tamanhos.

Embora o modelo DEA admita um número indiscriminado de fatores, sabe-se que quanto maior a quantidade de inputs e de outputs utilizados, maior pode ser o risco de perda do poder explicativo da análise de eficiência (Varela, 2008). Dyson et al. (2001) apontam que o número de DMUs deve ser pelo menos o dobro da multiplicação entre a quantidade de inputs e a quantidade de outputs. Neste estudo foram selecionados três inputs e quatro outputs, portanto, verifica-se que o critério foi atendido, uma vez que 2(3 x 4) = 24, e há 56 DMUs em análise.

As variáveis utilizadas na regressão logística foram escolhidas com base nos trabalhos de Postali (2012) e de Campello (2003), sendo elas: PIB per capita, participação do PIB agrícola no PIB total, Índice de Desenvolvimento Humano - Educação (IDHM - Educação ou IDHM-E) e População, que foram obtidos do IBGE (2014); e valor de ativos da prefeitura, despesas de capital, número de funcionários na administração direta do município e despesa com pessoal e encargos que foram obtidos na base de dados FINBRA/STN.

Entre as variáveis relativas à capacidade fiscal estão PIB per capita e a população municipal. Elas representam proxies para a riqueza do município e foram inseridas nas estimativas como controle para a capacidade fiscal municipal. Quanto maior o PIB per capita, maior a capacidade tributária. Por outro lado, localidades com elevados PIB per capita também tendem a possuir economias mais diversificadas, com estruturas produtivas mais complexas, as quais, por sua vez, demandam uma maior estrutura administrativa para o planejamento orçamentário e para a fiscalização de tributos. A variável população é uma variável controle para o tamanho do município, sob o pretexto de que cidades grandes coletam impostos de forma mais eficiente do que as pequenas. 
A participação do PIB agrícola no PIB total municipal auxilia no sentido de identificar a base tributária de um determinado município, uma vez que localidades rurais tendem a ser menos eficientes na arrecadação tributária, dada a dificuldade de coletar-se tributos em comparação com cidades mais urbanizadas.

O IDHM - Educação, por sua vez, visa identificar se municípios com maior grau médio de educação são mais eficientes no seu esforço fiscal.

O número de funcionários na administração direta municipal também pode indicar se a prefeitura possui adequado corpo de funcionários para as atividades tributárias do município. O número ideal seria se a variável fosse segregada pelas atividades e escolhido apenas o número de funcionários que efetivamente trabalham nas Secretarias de Finanças dos municípios, porém, os dados obtidos não possuíam este nível de segregação.

As variáveis relacionadas à despesa municipal (despesas administrativas, pessoal e encargos e despesas de capital) referem-se ao quanto as prefeituras remuneram o insumo trabalho. Estão incluídas informações sobre os vencimentos do pessoal civil e militar, encargos trabalhistas e obrigações patronais, contribuição previdenciária pública e para fundos de pensão.

O valor monetário de todo o ativo municipal, embora não represente uma receita municipal, será utilizado para construção da medida de preço de capital.

As despesas de capital, segundo definição dada pelo artigo 12 da Lei no 4.320/64, são os investimentos diretos (dotações para planejamento e a execução de obras, aquisição de material permanente e equipamentos, dentre outros), as inversões financeiras (aquisição de imóveis ou de bens de capital em utilização, aquisição de títulos de empresas) e a amortização de dívidas (Lei n. 4.320, de 17 de março de 1964, 1964). Estes dados podem auxiliar com informações sobre se localidades com maiores investimentos são mais eficientes nas coletas de tributos.

\section{ANÁLISE dos RESUltados}

Quanto às características dos municípios sob análise, a Tabela 1 apresenta a estatística descritiva da variável royalties recebidos pelos 56 Municípios entre os anos de 2005 a 2012, além do número de habitantes no mesmo período.

Tabela 1 - Dados dos 56 municípios do estado de São Paulo que receberam royalties entre 2005 e 2012

\begin{tabular}{|c|c|c|c|c|c|}
\hline Municípios & Média & Desvio padrão & $1^{\circ}$ quartil & Mediana & $3^{\circ}$ quartil \\
\hline População & $373.418,84$ & $1.466 .364,10$ & $28.574,50$ & $92.981,50$ & $265.632,25$ \\
\hline $\begin{array}{l}\text { Royalties } \\
(\mathrm{R} \$)\end{array}$ & $4.309 .729,25$ & $15.861 .733,08$ & $21.076,09$ & $31.180,73$ & $189.362,22$ \\
\hline $\begin{array}{l}\text { Royalties } \\
\text { per capita } \\
\text { (R\$) }\end{array}$ & 104,61 & 424,03 & 0,21 & 0,69 & 2,48 \\
\hline
\end{tabular}

Observa-se que o montante recebido, em média, é de aproximadamente $\mathrm{R} \$ 4$ milhões para municípios que possuem cerca de 370 mil habitantes. Além disso, é possível observar que a mediana dos royalties recebidos é de cerca de $\mathrm{R} \$ 31$ mil (contra os $\mathrm{R} \$ 4$ milhões em média) para municípios com mediana de 90 mil habitantes (contra 370 mil em média). Estas informações sugerem que existem municípios que recebem muitos royalties (que podem ser considerados como outliers) em relação ao resto da amostra, o que eleva a média e desvio padrão. Essa informação corrobora com os dados apresentados por Postali (2012), onde ele descreve uma forte assimetria entre os valores de royalties recebidos pelos municípios no país.

Os municípios que apresentaram maiores valores de royalties per capita, em ordem decrescente de royalties, são: Guararema, Ilhabela, São Sebastião, Bertioga, Ilha Comprida, Caraguatatuba, Cananéia, Cubatão e Iguape. Com exceção de Guararema, todos os outros municípios estão localizados no litoral de São Paulo. 
Para obter a eficiência técnica dos municípios avaliados utilizou-se o programa computacional Data Envelopment Analysis Computer Program (DEAP ), com modelo em um único estágio, com retorno de escala variável (equação (1)) e eficiência orientada ao produto. O resumo descritivo dos valores per capita das variáveis utilizadas são apresentados na Tabela 2.

Tabela 2 - Produtos e insumos utilizados na DEA

\begin{tabular}{|c|c|c|c|c|c|}
\hline Variável & Média & $\begin{array}{l}\text { Desvio } \\
\text { padrão }\end{array}$ & $\begin{array}{l}1^{\circ} \\
\text { quartil }\end{array}$ & Mediana & $\begin{array}{l}3^{\circ} \\
\text { quartil }\end{array}$ \\
\hline \multicolumn{6}{|l|}{$\begin{array}{l}\text { Produtos per } \\
\text { capita }\end{array}$} \\
\hline IPTU (R\$) & 202,65 & 241,30 & 48,86 & 120,29 & 255,11 \\
\hline ISSQN (R\$) & 172,74 & 210,27 & 41,82 & 90,92 & 211,14 \\
\hline ITBI (R\$) & 30,85 & 46,93 & 5,35 & 12,49 & 38,84 \\
\hline Taxas (R\$) & 42,51 & 52,06 & 11,10 & 20,18 & 48,18 \\
\hline \multicolumn{6}{|l|}{$\begin{array}{l}\text { Insumos per } \\
\text { capita }\end{array}$} \\
\hline $\begin{array}{l}\text { Transf. da União } \\
\text { (R\$) }\end{array}$ & 460,62 & 442,33 & 245,09 & 367,37 & 513,74 \\
\hline $\begin{array}{l}\text { Transf. dos } \\
\text { Estados }(\mathrm{R} \$)\end{array}$ & 494,15 & 440,70 & 254,68 & 372,80 & 558,46 \\
\hline Royalties (R\$) & 104,61 & 424,03 & 0,21 & 0,69 & 2,48 \\
\hline
\end{tabular}

Os valores de eficiência técnica para os 56 municípios são apresentados, em ordem alfabética, na Tabela 3. Mais da metade dos municípios avaliados foram considerados eficientes. Observa-se que, dos 56 municípios avaliados, 31 mostraram-se tecnicamente eficientes (a eficiência técnica do município é igual a 1). Em média, o valor da eficiência dos municípios foi de 0,87 e tanto a mediana como o terceiro quartil foram iguais a 1.

\section{Tabela 3 - Eficiência Técnica dos Municípios}

\begin{tabular}{|c|c|c|c|}
\hline Município & Efic_tec & Município & Efic_tec \\
\hline Arujá & 0,816 & Mauá & 0,775 \\
\hline Bertioga & 1 & Miracatu & 1 \\
\hline Biritiba-mirim & 0,939 & Moji das Cruzes & 1 \\
\hline Caieiras & 1 & Mongaguá & 0,895 \\
\hline Cajamar & 1 & Osasco & 0,957 \\
\hline Cananeia & 0,547 & Pariquera-açu & 1 \\
\hline Caraguatatuba & 0,731 & Pedro de Toledo & 0,492 \\
\hline Carapicuíba & 0,359 & Peruíbe & 0,833 \\
\hline Cotia & 1 & Pirapora do Bom Jesus & 1 \\
\hline Cubatão & 1 & Poá & 1 \\
\hline Diadema & 1 & Praia Grande & 0,665 \\
\hline Francisco Morato & 1 & Registro & 0,847 \\
\hline Franco da Rocha & 1 & Ribeirão Pires & 0,722 \\
\hline Guararema & 1 & Rio Grande da Serra & 0,959 \\
\hline Guarujá & 1 & Salesópolis & 0,726 \\
\hline Guarulhos & 0,845 & Santana de Parnaíba & 1 \\
\hline Iguape & 0,687 & Santo André & 1 \\
\hline Ilha Comprida & 1 & Santos & 1 \\
\hline Ilhabela & 0,341 & São Bernardo do Campo & 0,481 \\
\hline Itanhaém & 1 & São Caetano do Sul & 1 \\
\hline Itapecerica da Serra & 0,976 & São Lourenço da Serra & 1 \\
\hline Itapevi & 0,445 & São Paulo & 0,849 \\
\hline Itaquaquecetuba & 1 & São Sebastiao & 1 \\
\hline Itariri & 1 & São Vicente & 0,493 \\
\hline Jacupiranga & 0,675 & Sete Barras & 1 \\
\hline Jandira & 0,674 & Suzano & 1 \\
\hline Juquiá & 1 & Taboão da Serra & 1 \\
\hline Mairiporã & 1 & Vargem Grande Paulista & 1 \\
\hline
\end{tabular}




\begin{abstract}
Nota: Eficiência Técnica obtida pela análise DEA dos 56 municípios paulistas que receberam royalties de petróleo entre os anos de 2005 e 2012. A escala vai de 0 (ineficiência máxima) a 1 (eficiência), em que qualquer valor abaixo de 1 caracteriza-se como ineficiente.
\end{abstract}

A Tabela 4 apresenta a eficiência técnica dos nove municípios com maiores rendas de petróleo per capita contidos na amostra. Os municípios de Guararema, São Sebastião, Bertioga, Ilha Comprida e Cubatão mostraram-se eficientes, ao passo que Ilhabela, Caraguatatuba, Cananéia e Iguape foram considerados ineficientes, ou seja, os municípios estão divididos quase que igualmente entre eficientes e ineficientes. Diante disso, somente com esses resultados não é possível concluir se os royalties do petróleo influenciam no esforço fiscal do município.

Tabela 4 - Eficiência dos municípios com maiores royalties per capita

$\begin{array}{llllll}\text { Município } & \text { Eficiência } & \begin{array}{l}\text { Royalties per } \\ \text { capita (R\$) }\end{array} & \text { Município } & \text { Eficiência } & \begin{array}{l}\text { Royalties per } \\ \text { capita (R\$) }\end{array} \\ \text { Guararema } & 1 & 1.138,20 & \text { Caraguatatuba } & 0,731 & 339,53 \\ \text { Ilhabela } & 0,341 & 1.091,57 & \text { Cananeia } & 0,547 & 178,44 \\ \text { São Sebastiao } & 1 & 1.007,27 & \text { Cubatão } & 1 & 102,68 \\ \text { Bertioga } & 1 & 690,15 & \text { Iguape } & 0,687 & 33,36 \\ \text { Ilha } & 1 & 548,30 & & & \\ \text { Comprida } & & & & & \end{array}$

O segundo estágio na análise, com o modelo de regressão logística, visa verificar quais variáveis poderiam causar a ineficiência dos municípios. O programa computacional utilizado para obter as estimativas desse modelo foi o programa R. O resumo descritivo dos valores per capita das variáveis utilizadas na regressão logística encontra-se na Tabela 5.

Tabela 5 - Variáveis independentes utilizadas na Regressão Logística

\begin{tabular}{|c|c|c|c|c|c|}
\hline Variável & Média & Des. padrão & $1^{\circ}$ quartil & Mediana & $3^{\circ}$ quartil \\
\hline $\mathrm{PIB}(\mathrm{R} \$$ mil) & $12.819,13$ & $15.349,83$ & $7.335,58$ & $9.179,69$ & $16.400,22$ \\
\hline PO - PIB & 0,04 & 0,07 & 0 & 0 & 0,02 \\
\hline População & $373.418,84$ & $1.466 .364,10$ & $28.574,50$ & $92.981,50$ & $265.632,25$ \\
\hline IDHM - Educação & 0,64 & 0,05 & 0,66 & 0,70 & 0,72 \\
\hline Ativo $(\mathrm{R} \$$ mil) & $4.155,14$ & $5.106,88$ & $1.223,38$ & $2.618,94$ & $4.970,00$ \\
\hline $\begin{array}{l}\text { Desp. de Capital (por } \\
\text { ativo) }\end{array}$ & 0,11 & 0,21 & 0,05 & 0,08 & 0,13 \\
\hline $\begin{array}{l}\mathrm{N}^{0} \text { de func. (por mil } \\
\text { hab.) }\end{array}$ & 27,21 & 12,73 & 18,06 & 24,56 & 32,37 \\
\hline $\begin{array}{l}\text { Pessoal e encarg. (por } \\
\text { func.) }\end{array}$ & $30.522,35$ & $13.736,14$ & $21.453,79$ & $27.034,51$ & $35.471,72$ \\
\hline
\end{tabular}

As variáveis explicativas PIB per capita, população, ativos per capita, número de funconários a cada mil habitantes e pessoal e encargos por funcionários foram utilizadas na forma logarítmica, ao passo que as variáveis participação do PIB agrícola no produto municipal, o Índice de desenvolvimento humano municipal educação (IDHM - Educação) e as despesas de capital por ativo foram utilizadas na escala original.

Frente à presença de muitas variáveis explicativas utilizou-se, inicialmente, um método de seleção de variáveis para modelos de regressão logística (disponível no pacote "bestglm" do programa R) em que são avaliadas todas as possíveis combinações de variáveis explicativas e aquela combinação que apresentar menor AIC será a combinação escolhida.

A Tabela 6 apresenta as estimativas, o erro padrão e a estatística de Wald do modelo de regressão logística. As variáveis participação do PIB agrícola no produto municipal, IDHM - Educação, Ativo per capita, 
número de funcionários a cada mil habitantes e despesa de pessoal e encargos por funcionários foram significativas a $10 \%$.

Tabela 6 - Regressão Logística sem as variáveis PIB per capita e população para a eficiência técnica (variável dependente)

\begin{tabular}{|c|c|c|c|c|}
\hline Coeficientes & Estimativa & Erro padrão & $\begin{array}{c}\text { Valor } \\
\mathbf{z}\end{array}$ & $\operatorname{Pr}(P|z|)$ \\
\hline Intercepto & $-48,9313$ & 19.3270 & -2.532 & $0,0114 *$ \\
\hline PO PIB & $-14,6500$ & 7,7552 & $-1,889$ & 0,0588 . \\
\hline IDHM - Educação & $-20,3870$ & 11,9310 & $-1,709$ & 0,0875 . \\
\hline Ln ativo per capita) & $-1,6216$ & 0,8142 & $-1,992$ & $0,0464 *$ \\
\hline Desp. de capital por ativo & 6,9015 & 5,0695 & 1,361 & 0,1733 \\
\hline Ln (func por mil hab.) & 3,4334 & 1,3643 & 2,517 & $0,0118 *$ \\
\hline $\begin{array}{c}\text { Ln (pessoal e encargo por } \\
\text { func.) }\end{array}$ & 6,3108 & 2,2236 & 2,838 & $0,0045 * *$ \\
\hline
\end{tabular}

Níveis de significância: ${ }^{(* * *)}<1 \%{ }^{(* *)}<5 \%^{(*)}<10 \%$

A participação do PIB agrícola no PIB total do município (PO PIB) mostrou-se negativa e significativa a $10 \%$ (Tabela 6), o que denota que um município com maior participação rural no seu PIB teria maior chance de ser menos eficiente em seu esforço fiscal. Isso pode ser explicado por uma possível dificuldade de se mensurar e coletar tributos nestas áreas (Postali, 2012). Além disso, produtores rurais possuem diversas isenções tributárias e obrigações acessórias simplificadas, o que pode prejudicar o trabalho de fiscalização tributária.

O IDHM - Educação mostrou-se negativo e significativo a 10\%, indo de encontro à ideia de que quanto maior o nível educacional do município, mais eficiente seria sua gestão fiscal. A variável referente aos ativos também mostrou-se negativa (significante a 5\%), podendo indicar que maiores gastos das prefeituras na incorporação de ativos, aumentam as chances de o município não direcionar recursos às atividades coletoras de tributos.

Por outro lado, o número de funcionários e o gasto com pessoal e encargos mostraram-se positivos (significantes a $5 \%$ e a $1 \%$, respectivamente), indicando que prefeituras que realizam maiores gastos com seus funcionários potencializam positivamente as chances de serem eficientes na coleta de tributos.

Para verificar a adequabilidade do modelo obteve-se também as estatísticas Pseudo- $\mathrm{R}^{2}$, comumente utilizadas nos modelos de regressão logística (Serra et al., 2014), tais como, $\mathrm{R}^{2}$ de Cox e Snell (0,2746), $\mathrm{R}^{2}$ de Nagelkerke (0,3675), $\mathrm{R}^{2}$ de McKelvey Zavoina (0,4430). Os critérios AIC $(73,0122)$ e AIC corrigido $(75,3455)$ foram utilizados para a escolha do melhor modelo (o melhor modelo é aquele que possui o menor AIC). Para verificar se o modelo logístico tem um valor aceitável, utilizou-se o teste de Hosmer e Lemeshow onde encontrou-se $\mathrm{p}$-valor $=0,3518$, não rejeitando a hipótese de que os valores reais e esperados sejam iguais.

Uma última análise para verificar a capacidade preditiva do modelo dá-se através da comparação da classificação anterior à análise com a classificação posterior. Inicialmente os municípios poderiam ser classificados, caso o modelo se deixasse guiar apenas pela situação em se enquadra a maioria dos municípios observados. Observa-se na Tabela 7 (colunas do lado esquerdo da Tabela 7) que a amostra contem 31 municípios eficientes e 25 ineficientes. Se nenhuma variável explicativa fosse incluída no modelo, a priori todos os municípios seriam classificados como eficientes, portanto, o percentual de acerto nas classificações seria de $60,7 \%$. 
Tabela 7 - Classificação dos municípios anterior à análise

\begin{tabular}{llll}
$\begin{array}{l}\text { Valores } \\
\text { observados }\end{array}$ & \multicolumn{3}{l}{$\begin{array}{l}\text { Valores preditos } \\
\text { Classificação anterior à análise } \\
\text { Eficiente }\end{array}$} \\
& Ineficiente & $\%$ de acerto \\
$\begin{array}{l}\text { Eficiente } \\
\text { Ineficiente }\end{array}$ & 31 & 0 & 100 \\
\% geral & 25 & 0 & 0 \\
& & & 60,7
\end{tabular}

\begin{tabular}{|c|c|c|}
\hline Eficiente & Ineficiente & $\begin{array}{l}\% \text { de } \\
\text { acerto }\end{array}$ \\
\hline 24 & 7 & 77,4 \\
\hline 9 & 16 & $\begin{array}{l}64,7 \\
71,4\end{array}$ \\
\hline
\end{tabular}

Ao incluir as variáveis explicativas no modelo obteve-se a classificação a posteriori (colunas do lado direto da Tabela 7) e observa-se que o modelo aumentou a extidão das predições para $71,4 \%$, portanto, pode-se concluir que estatisticamente é viável incluir as variáveis independentes no modelo.

Considerando todos os resultados conjuntamente, conclui-se que as variáveis explicam a eficiência dos municípios no período observado.

\section{CONCLUSÃO}

O objetivo deste trabalho foi investigar a hipótese de que as rendas do petróleo, distribuídas de acordo com o regrado na Lei do Petróleo, poderiam gerar ineficiências na administração tributária dos municípios beneficiados, principalmente naqueles em que as rendas do petróleo fossem significativas.

Os resultados indicaram que, dentre os 56 municípios avaliados, dentro do estado de São Paulo, 31 mostraram-se tecnicamente eficientes. Foi realizada ainda uma análise nos nove municípios da amostra que apresentaram maior receita de royalties per capita. Verificou-se que, dos nove municípios selecionados, com exceção de Guararema, todos ficam no litoral paulista. Nessa análise, cinco municípios foram considerados eficientes, ao passo que os outros quatro foram considerados ineficientes. Apenas com esses resultados não foi possível concluir se os royalties de petróleo influenciam no esforço fiscal do município. Vale destacar a característica do modelo DEA de que a fronteira eficiente revelada pode não ser a fronteira eficiente efetiva, uma vez que as DMUs (municípios) são consideradas eficientes somente no comparativo com as outras DMUs da amostra em análise.

Ao empreender o segundo estágio da análise, por meio da Regressão Logística, identificou-se que as variáveis "participação do PIB agrícola sobre o produto total do município", o "IDHM - Educação" e o "valor dos ativos per capita" apresentaram influência negativa na probabilidade de o município ser eficiente tecnicamente em sua gestão tributária. Por outro lado, o "número de funcionários na administração direta" e as "despesas com pessoal e encargos" mostraram influência positiva na probabilidade de o município ser eficiente em seu esforço fiscal.

Estes resultados denotam que um município com maior participação rural em seu PIB teria maior chance de ser menos eficiente em seu esforço fiscal. Outro resultado mostra que quanto maior o nível educacional do município, mais eficiente seria sua gestão fiscal. Outra indicação é que quanto maiores os gastos das prefeituras na incorporação de ativos, aumentam as chances de o município não direcionar recursos às atividades coletoras de tributos. Por outro lado, prefeituras que realizam maiores gastos com seus funcionários potencializam positivamente as chances de serem eficientes na coleta de tributos.

Dentre as limitações deste estudo, apresenta-se o fato de que os dados referentes à distribuição das rendas do petróleo, no período e nos municípios pesquisados, mostraram-se com alta variabilidade. Isso se deve às regras de distribuição dos royalties de petróleo, definidas pelo Marco Regulatório, que implicam em uma grande concentração de recursos nas receitas de poucos municípios. Por isso, em poucos municípios paulistas as rendas do petróleo mostraram-se significativas o suficiente para poderem ser consideradas como indutoras de um comportamento relaxador do esforço fiscal. 


\section{REFERÊNCIAS}

Afonso, António, Fernandes, Sónia. Assessing and explaining the relative efficiency of local government. The Journal of Socio-Economics, Beer Sheva, v. 37, n. 5, p. 1946-1979, Oct. 2008.

Agência Nacional do Petróleo, Gás Natural e Biocombustíveis (ANP). Anuário Estatístico Brasileiro do Petróleo, Gás Natural e Biocombustíveis: 2014. Rio de Janeiro. 2014. Disponível em: http://www.anp.gov.br/?pg=71976 . Acesso em: 20 jan. 2015.

Araújo, Pedro Lucas da C. P. Efcciência tributária em dois estágios: a análise envoltória de dados (DEA) e regressão quantílica. 2007. 63 f. Dissertação (Mestrado em Economia), Universidade de Brasília - UNB. Brasília, 2007.

Balaguer-Coll, Maria T., Prior, Diego, Tortosa-Ausina, Emili. On the determinants of local government performance: a two-stage nonparametric approach. European Economic Review, Amsterdam, v. 51, n. 2, p. 425-451, Feb. 2007.

Banker, Rajiv D., Charnes, A., Cooper, William W. Some models for estimating technical and scale inefficiencies in data envelopment analysis. Management science, Linthicum, v. 30, n. 9, p. 1078-1092, Sept. 1984.

Lei n. 4.320, de 17 de março de 1964. (1964). Estatui Normas Gerais de Direito Financeiro para elaboração e controle dos orçamentos e balanços da União, dos Estados, dos Municípios e do Distrito Federal. Disponível em: http://www.planalto.gov.br/ccivil_03/Leis/L4320.htm;. Acesso em: 30 nov. 2014. (Error 19: El enlace externo http://www.planalto.gov.br/ccivil_03/Leis/L4320.htm> debe ser una URL) (Error 20: La URL http:// www.planalto.gov.br/ccivil_03/Leis/L4320.htm> no esta bien escrita)

Lei n. 4.320, de 17 de março de 1964. (1964). Estatui Normas Gerais de Direito Financeiro para elaboração e controle dos orçamentos e balanços da União, dos Estados, dos Municípios e do Distrito Federal. Disponível em: . Acesso em: 30 nov. 2014.

Lei n. 12.734, de 30 de novembro de 2012. (2012). Modifica as Leis no 9.478, de 6 de agosto de 1997, e no 12.351, de 22 de dezembro de 2010, para determinar novas regras de distribuição entre os entes da Federação dos royalties e da participação especial devidos em função da exploração de petróleo, gás natural e outros hidrocarbonetos fluidos, e para aprimorar o marco regulatório sobre a exploração desses recursos no regime de partilha. Disponível em: http://www.planalto.gov.br/CCIVIL_03/_Ato2011-2014/2012/Lei/L12734.htm;. Acesso em: 30 nov. 2014.

Campello, Carlos Alberto G. B. Eficiência municipal: um estudo no estado de São Paulo. 2003. 205 f. Tese (Doutorado em Administração de Empresas)-Universidade de São Paulo - USP, São Paulo, 2003.

Charnes, A., Cooper, William W., Rhodes, Edwardo. Measuring the efficiency of decision making units. European Journal of Operational Research, Amsterdam, v. 2, n. 6, p. 429-444, Nov. 1978.

Cossio, Fernando A. B. Disparidades inter-regionais, Capacidades de Obtenção de Recursos Tributários. Esforço Fiscale Gasto Público no Federalismo Brasileiro. Rio de Janeiro: BNDES, 1998.

Dias Filho, José M., Corrar, Luiz J. Regressão Logística. In: corrar, luiz j., paulo, edilson, dias filho, josé m. (Org.). Análise Multivariada: para cursos de administração, ciências contábeis e economia. Fundação Instituto de Pesquisas Contábeis, Atuariais e Financeiras - FIPECAFI. São Paulo: Atlas, 2007. cap. 5, p. 280-323.

Diniz, Josedilton A. Eficiência das transferências intergovernamentais para a educação fundamental de Municípios brasileiros. 2012. 167 f. Tese (Doutorado em Ciências)- Universidade de São Paulo-USP, São Paulo, 2012.

Dyson, Robert G. Et Al. Pitfalls and protocols in DEA. European Journal of Operational Research, Amsterdam, v. 132, n. 2, p. 245-259, July. 2001.

Ibge. Divulga os resultados do Sistema de Contas Nacionais relativos às tabelas de recursos e usos, contas econômicas integradas, contas regionais do Brasil, produto interno bruto dos Municípios e matriz de insumo-produto. Contas Nacionais, Rio de Janeiro, n. 42, 2014. Disponível em: <ftp://ftp.ibge.gov.br/Contas_Regionais/2012/ pdf/contas_regionais_2012.pdf.>. Acesso em: 30 nov. 2014.

Koopmans, Tjalling C. Activity analysis of production and allocation. New York: Wiley, 1951

Leal, José A. A., Serra, Rodrigo V. Notas sobre os Fundamentos Econômicos da Distribuição Espacial dos Royalties Petrolíferos no Brasil. In: ENCONTRO NACIONAL DA ANPEC, 30., 2002, Nova Friburgo (RJ). Anais. Nova Friburgo: ANPEC, 2002. 
Lopes, Marcos F. M., Arvate, Paulo R. Vertical fiscal imbalance e eficiência técnica do gasto público municipal: um estudo para os Municípios do estado de São Paulo. In: ENCONTRO DE ADMINISTRAÇÃO PÚBLICA E GOVERNANÇA -ENAPG, 2., 2006, São Paulo. Anais. Rio de Janeiro: ANPAD, 2006.

Navarro, Carlos A. Royalties do petróleo: estudo de caso de Campos dos Goytacazes. 2003. 85 f. Dissertação (Mestrado em Economia Empresarial)-Universidade Cândido Mendes, Rio de Janeiro, 2003.

Nogueira, Lauro C. B, Ramos, Francisco S. Uma proposta de distribuição dos royalties do petróleo introduzindo critérios de eficiência: uma abordagem DEA. 2013. 17 f. Programa de Pós-Graduação em Economia-PPGE, Universidade Federal da Paraíba, João Pessoa, 2013. Disponível em: http://www.ccsa.ufpb.br/ppge/arquivos/ ensaios/TD18_2013.pdf;. Acesso em: 14 dez.2014. (Error 25: El enlace externo http://www.ccsa.ufpb.br/ppge/ arquivos/ensaios/TD18_2013.pdf> debe ser una URL) (Error 26: La URL http://www.ccsa.ufpb.br/ppge/ arquivos/ensaios/TD18_2013.pdf > no esta bien escrita)

Oates, Wallace E. Fiscal federalism. New York: Hartcourt Brace Jovanovich, 1972

Postali, Fernando A. S. Petroleum royalties and regional development in Brazil: the economic growth of recipient towns. Resources Policy, [S. 1.], v.34, n. 4, p. 205-213, Dec. 2009.

Postali. Rendas do petróleo e ineficiências administrativas nos Municípios brasileiros. 2012. 112 f. Tese (Livre Docência em Economia)-Faculdade de Economia, Administração e Contabilidade, Universidade de São Paulo, São Paulo, 2012. Disponível em: http://www.teses.usp.br/teses/disponiveis/livredocencia/12/ tde-18012013-093111. Acesso em: 08 abr. 2013.

Postali, Nishijima, Marislei. Distribuição das rendas do petróleo e indicadores de desenvolvimento municipal no Brasil nos anos 2000s. Estudos Econômicos, São Paulo, v. 41, n. 2, p. 463-485, abr./jun. 2011.

Reis, Diego A., Santana, José R. Os efeitos da aplicação dos royalties petrolíferos sobre os investimentos públicos nos municípios brasileiros. Revista de Administração Pública, Rio de Janeiro, v. 49, n. 1, p. 91-117, jan./fev. 2015.

Sanguinetti, Pablo, Tommasi, Mariano. Intergovernmental transfers ad fiscal behavior insurance versus aggregate discipline. Journal of International Economics, v. 62, n.1, p. 149-70, 2004.

Serra, Ricardo G. et al. Market Crash, características das empresas e retorno - uma análise logística e discriminante. Revista de Contabilidade da UFBA, Salvador, v. 8, n. 1, p. 21-36, jan./abr. 2014.

Serra, Rodrigo V. Contribuições para o debate acerca da repartição dos royalties petroliferos no Brasil. 2005. 289 f. Tese (Doutorado em Economia)-Instituto de Economia, Universidade de Campinas, Campinas, 2005. Disponível em: <http://www.bibliotecadigital.unicamp.br/document/?code= vtls000431975\&opt=1>. Acesso em: 04 maio 2014.

Serra, Rodrigo V. Desdobramento espacial da exploração e produção de petróleo no Brasil: em busca de um nexo para a exploração de petróleo entre os Municípios. In: ENCONTRO NACIONAL DA ANPUR, 10., 2003, Belo Horizonte. Anais do X ENA. Recife: ANPUR, 2003.

Smart, Michael. Taxation and deadweight loss in a system of intergovernmental transfers. The Canadian Journal of Economics/Revue canadienne d'Economique, v. 31, n.1, p.189-20, 1998.

Shah, Anwar. The reform of intergovernmental fiscal relations in developing and emerging market economies. Policy and Research Series no 23. The World Bank, 1994.

Varela, Patrícia S. Financiamento e controladoria dos Municípios paulistas no setor saúde: uma avaliação de eficiência. 2008. 211 f. Tese (Doutorado em Ciências Contábeis)-Faculdade de Economia, Administração e Contabilidade, Universidade de São Paulo, São Paulo, 2008. Disponível em: http://www.teses.usp.br/ teses/disponiveis/12/12136/tde-19012009-113206/pt-br.php/;. Acesso em: 16 set. 2014. (Error 27: El enlace externo http://www.teses.usp.br/teses/disponiveis/12/12136/tde-19012009-113206/pt-br.php/> debe ser una URL) (Error 28: La URL http://www.teses.usp.br/teses/disponiveis/12/12136/tde-19012009-113206/ pt-br.php/> no esta bien escrita)

Varela, Patrícia S., Martins, Gilberto De A., Fávero, Luiz P. L. Desempenho dos Municípios paulistas: uma avaliação de eficiência da atenção básica à saúde. Revista de Administração (FEA-USP), São Paulo, v. 47, p. 624-637, out./ nov./dez. 2012. 
Douglas Schiavoni Froemming, et al. A Distribuição dos Royalties do Petróleo e a Eficiência na Ges...

Worthington, Andrew C. Cost efficiency in Australian local government: a comparative analysis of mathematical programming and econometrical approaches. Financial Accountability \& Management, [S. 1.], v. 16, n. 3, p. 201-223, Aug. 2000.

CC BY-NC-ND 